\title{
Design, Assembly, and Commissioning of a Cryogenic DC Current Transformer Designed for Measuring Currents of up to $80 \mathrm{kA}$
}

\author{
G. Montenero, A. Ballarino, L. Bottura \\ CERN, Geneva, Switzerland \\ P. Arpaia \\ Dipartimento di Ingegneria, Università del Sannio, 82100 Benevento, Italy
}

Keywords: Cryogenic temperatures, measurement current, transformers, superconducting coils, superconducting devices

\begin{abstract}
A new cryogenic dc current transformer (Cryo-DCCT) has recently been designed and assembled at CERN. The device, whose design is based on that of a high-accuracy 600 A market solution suitable for room temperature applications, is optimized for measuring currents of up to $80 \mathrm{kA}$ and for operation at $4.2 \mathrm{~K}$. The CryoDCCT has been conceived with the objective of preserving the metrological performance of the original commercial device in the new extended range of operation. For reducing the effect of interfering magnetic fields arising from test conditions, it incorporates ferromagnetic and MgB2 superconducting shields. In this paper, the design of the CryoDCCT and the results of the commissioning of the device at CERN are reported. The effectiveness of the current transducer is analysed and discussed. This new device will be used for measuring the secondary current of a $80 \mathrm{kA}$ superconducting transformer feeding a sample of $\mathrm{NbSn} 3$ cable at the Facility for Research on Superconducting Cables (FRESCA) at CERN.
\end{abstract}

Presented at: ASC 2014, 10-15 August, Charlotte, USA

Geneva, Switzerland

June 2015 


\title{
Design, Assembly, and Commissioning of a Cryogenic DC Current Transformer Designed for Measuring Currents of up to $80 \mathrm{kA}$
}

\author{
G. Montenero, P. Arpaia, A. Ballarino, and L. Bottura
}

\begin{abstract}
A new cryogenic de current transformer (CryoDCCT) has recently been designed and assembled at CERN. The device, whose design is based on that of a high-accuracy $600 \mathrm{~A}$ market solution suitable for room temperature applications, is optimized for measuring currents of up to $80 \mathrm{kA}$ and for operation at $4.2 \mathrm{~K}$. The CryoDCCT has been conceived with the objective of preserving the metrological performance of the original commercial device in the new extended range of operation. For reducing the effect of interfering magnetic fields arising from test conditions, it incorporates ferromagnetic and $\mathrm{MgB}_{2}$ superconducting shields. In this paper, the design of the CryoDCCT and the results of the commissioning of the device at CERN are reported. The effectiveness of the current transducer is analysed and discussed. This new device will be used for measuring the secondary current of a $80 \mathrm{kA}$ superconducting transformer feeding a sample of $\mathrm{NbSn}_{3}$ cable at the Facility for Research on Superconducting Cables (FRESCA) at CERN.
\end{abstract}

Index Terms-Cryogenic temperatures, measurement current transformers, superconducting coils, superconducting devices.

\section{INTRODUCTION}

A SSESSMENT of the electrical performance of superconducting cables is carried out measuring the voltagecurrent characteristic (V-I curve) of a cable as a function of temperature and magnetic field [1]. From an operating point of view, V-I measurements are straightforward at a given temperature. A magnet provides the desired level of background magnetic flux density while a DC power supply ramps up the current into the sample till a quench occurs. The voltage drop across the sample under test is measured through taps disposed along the cable. This procedure seems to be rather simple, but the required degree of complexity for the implementation of a test facility becomes evident considering the need for $\mathrm{i}$ ) a dedicated cryogenic system, ii) currents of the order of tens of $\mathrm{kA}$, and iii) superconducting magnets for background fields of several $\mathrm{T}$ (for example [2]-[5]). Moreover, high-accuracy measurements of both current and voltage are crucial for test results. When high currents are required for the measurements, supercon-

Manuscript received August 8, 2014; accepted November 10, 2014. Date of publication November 13, 2014; date of current version December 15, 2014.

G. Montenero was with the Dipartimento di Ingegneria, Università del Sannio, 82100 Benevento, Italy. He is now with CERN-European Laboratory for Nuclear Research, 1211 Geneva, Switzerland (e-mail: giuseppe.montenero@ cern.ch).

P. Arpaia is with the Dipartimento di Ingegneria, Università del Sannio, 82100 Benevento, Italy (e-mail: arpaia@unisannio.it).

A. Ballarino and L. Bottura are with the Department of Technologies, CERNEuropean Laboratory for Nuclear Research, 1211 Geneva, Switzerland (e-mail: amalia.ballarino@cern.ch; luca.bottura@cern.ch).

Digital Object Identifier 10.1109/TASC.2014.2370452 ducting transformers become an interesting alternative to highcurrent DC power converters [4], [6]-[10]. On the other hand, in addition to the difficulty of operating a superconducting transformer [11], a major metrological issue is the measurement of the transformer's secondary current, which is the current flowing in the cable under test. The current must be measured via contactless sensors capable of working at cryogenic temperatures [12] (interruptions of the superconducting circuit have to be avoided). Widely used current sensors are Rogowski and pick up coils [6], [7], [9], [11]. This classical solution has drawbacks such as intrinsic AC nature and limited measurement time due to the need of low drift integration (to keep accuracy of the measured current within the range of hundreds of ppm [11]). A transducer that can overcome the aforementioned drawbacks is a DC Current Transformer (DCCT). Commercial DCCT, for room temperature applications, are capable of sensing DC currents having bandwidth of the order of hundreds of $\mathrm{kHz}$ with accuracy better than $100 \mathrm{ppm}$.

A new insert, tailored for hosting a superconducting transformer recently inherited from the CEA laboratory, has been designed and assembled to increase the maximum testing current from $32 \mathrm{kA}$ to $80 \mathrm{kA}$ at the Facility For Research on Superconducting Cable (FRESCA) at CERN [2]. The superconducting transformer reached a maximum current of $80 \mathrm{kA}$ [13] at the CEA test facility. At CEA, the current in the secondary of the transformer was measured using a DC current transformer (DCCT) up to $60 \mathrm{kA}$ [14] and from that current on with a pickup coil [9]-[13]. This first attempt to implement a DCCT capable of operating at $4.2 \mathrm{~K}$ was successful, but the device was not able to cover the whole operation range of the transformer.

The development performed at CEA was based on the idea of modifying a commercial DCCT and extending its working conditions at $4.2 \mathrm{~K}$ to measure currents of up to $100 \mathrm{kA}$. The main implication of this approach was to keep the device's sensing element unaltered as much as possible.

In a previous paper [15], the authors reported on the design of a new cryogenic sensing element for a DCCT capable to overcome the aforementioned limitation. The proposed sensor is based on: An optimized geometrical design of the sensing element, exploitation of a magnetic alloy suitable for cryogenic applications (referred to as cryogenic permalloy), and mitigation of cores saturation through a combination of ferromagnetic and superconducting shield [16]. As proof of concept, the characterization of a demonstrator rated at $20 \mathrm{kA}$ was described. The demonstrator was built to verify the suitability of the cryogenic permalloy as a material for the ferromagnetic DCCT's cores. 


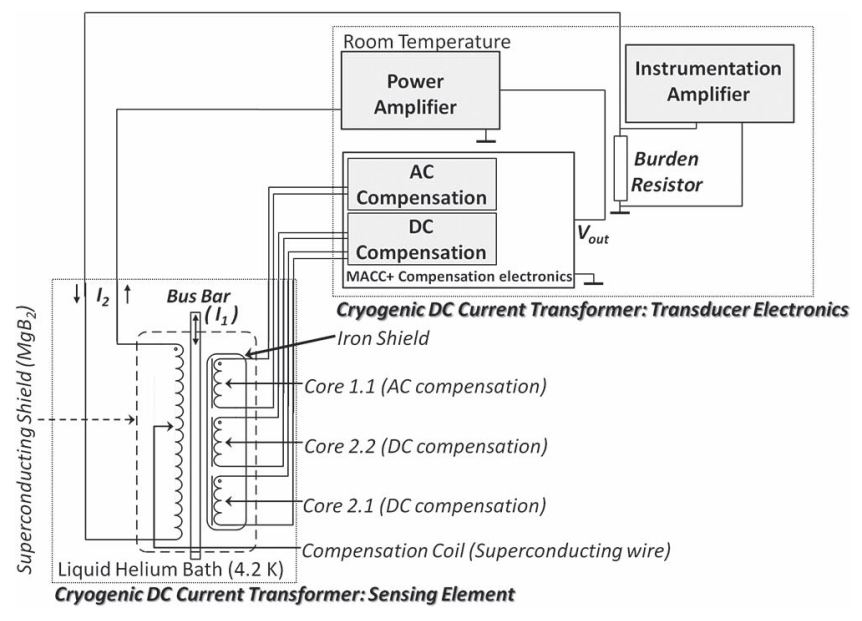

Fig. 1. Architecture of the cryogenic DC current transformer.

In this paper, the final Cryogenic DCCT prototype (CryoDCCT), which will be installed in the new $80 \mathrm{kA}$ superconducting transformer operated at the FRESCA test station is presented. Then, the metrological characterization of the new device showing the effectiveness of development up to $76 \mathrm{kA}$ is illustrated. In Section II, the design principles of the CryoDCCT are recalled and attention is also paid to the assembly of the new sensing element. Section III details the experimental set-up used to characterize the device, while Section IV reports on the results of the test campaign on the CryoDCCT.

\section{Cryogenic DC CURrent Transformer}

The architecture of the new CryoDCCT is shown in Fig. 1. The working principle of the device is based on the wellknown zero flux compensation mechanism [18], for both AC and DC current components [18]-[20], to achieve the ideal current transformer ratio: $N_{1} I_{1}=-N_{2} I_{2}$.

The unknown current $\left(I_{1}\right)$ is measured trough the voltage on the burden resistor $\left(\mathrm{V}_{\text {burden }}=-\mathrm{R}_{\text {burden }}\left(N_{1} I_{1}\right) / N_{2}\right)$. An instrumentation amplifier is implemented to map $100 \mathrm{kA}$ current into a $10 \mathrm{~V}$ signal for a precision burden resistor of $50 \mathrm{~m} \Omega$.

In the design of the new CryoDCCT, the conditioning electronics from a commercial 600 A DC current transformer $(\mathrm{MACC}+[21])$ is reused. This required the implementation of a new power amplifier and a new sensing element with optimized design for a rated current of $100 \mathrm{kA}$ at $4.2 \mathrm{~K}$.

\section{A. Conditioner Electronic}

The MACC+ is a commercial DC current transformer capable of measuring currents of up to $600 \mathrm{~A}$ with accuracy of $10 \mathrm{ppm}$. This transducer accuracy is obtained combining an optimized sensing element and conditioning electronics. We decided to use the available electronics to minimize the development of new circuitry. Fig. 1 highlights the MACC+ electronic components on which the CryDCCT is based, that is, the $\mathrm{AC}$ and $\mathrm{DC}$ compensation. However, a minor adjustment of the DC compensation part was required to operate the CryoDCCT properly. In particular, the excitation current of Cores 2.1 and 2.2 is increased by a factor two to achieve the required level of core saturation.
The abovementioned choice allowed then to focus on the optimized design of components, such as the Power Amplifier and the Sensing Element, to implement a new device with extended range of operation.

\section{B. New Power Amplifier}

A DCCT can be seen as an ideal current transformer, where the secondary current $I_{2}$ has to be supplied by a power amplifier. The MACC+ power amplifier can generate maximum $1 \mathrm{~A}$, that means a coil of 80000 turns would be required for $80 \mathrm{kA}$. Hence, the implementation and performance of such a device would be critical [15]-[22]. Consequently, a new power stage is required. The developed power amplifier for the CryoDCCT is rated at $10 \mathrm{~A}$. The design is aimed at preserving the performance of MACC+ trough a similar classical bipolar amplifier. Two complementary Darlington transistors (2N6827, 2 N6824) are biased trough resistances of $42.2 \Omega$ and $487 \Omega$. A limiting resistor of $0.8 \Omega$ provides the operation in the safeactive region. Moreover, a buffer circuit (OP27, BUF634) is added between the MACC+ control output $\left(V_{\text {out }}\right.$, Fig. 1$)$ and the biasing resistance network to guarantee the required current.

\section{Optimized Sensing Element}

As previously stated, the design of a sensing element for a DCCT rated at $80 \mathrm{kA}$ working at $4.2 \mathrm{~K}$ is a challenging task. In [20] it is clearly recalled that the magnetic circuit has to be designed with the aim of (i) increasing the sensitivity to the primary magnetic field (generated by the unknown current), (ii) minimizing the sensitivity to external magnetic fields and (iii) minimizing the sensitivity to the sensing element centring and to the return bus-bar configuration. High sensitivity to the primary magnetic field is guaranteed using soft magnetic material with high magnetic permeability and low coercive force. In this regard, MACC+'s cores are implemented using $\mu$-metal material to achieve best performance. For this reason, it is of foremost importance to choose CryoDCCT core's magnetic alloy with high-uniformity characteristics at $4.2 \mathrm{~K}$, as close as possible to the $\mu$-metal characteristics at room temperature, to preserve high sensitivity to unknown currents. Then, an optimized geometrical cores' design has to be carried out with the aim of keeping the sensing element in a zero-flux condition (or within a maximum required accuracy) at the rated current of $100 \mathrm{kA}$ (refer to [14] for the optimization process). Primary bus-bar off-centering is addressed using an iron magnetic shield. Sensitivity to external magnetic field, due also to the return bus-bar, is minimized by means of a cy lindrical superconducting shield made of $\mathrm{MgB}_{2}$ composite [16]. In Fig. 2, the cross section view of the optimized sensing element is reported.

The cores of the CryoDCCT are wound with a tape of soft Ni 81-Mo 5-Fe magnetic alloy (referred to as cryogenic permalloy [23]), having a thickness of $0.2 \mathrm{~mm}$. In Fig. 3(a), one of the cores used for the CryoDCCT sensing element with the optimized dimensions is shown. The sensing coil (200 turns) is insulated from a core through Teflon tape (thickness of $0.1 \mathrm{~mm}$ ). Teflon is also used to mutually insulate the three cores (see Fig. 3(b)). 


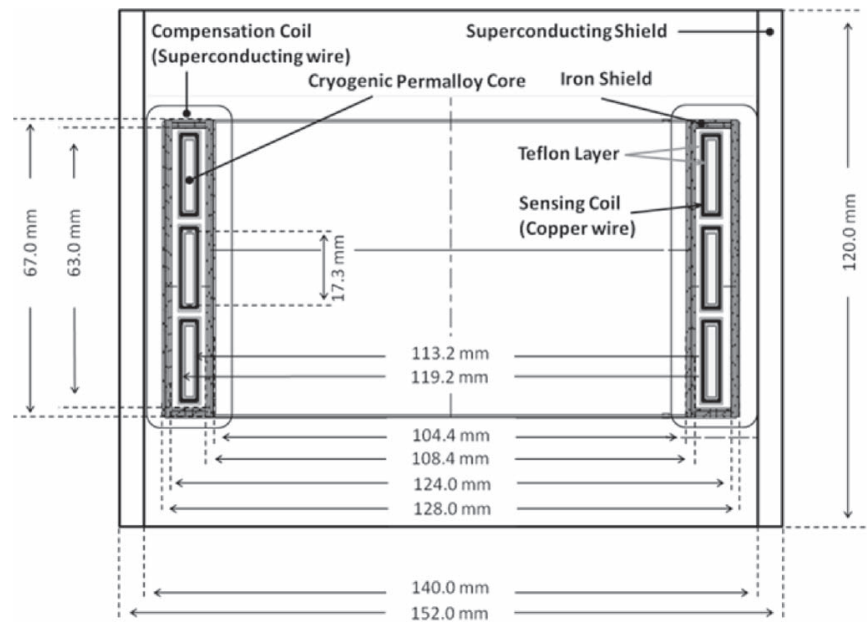

Fig. 2. Cross-section view of the optimized CryoDCCT sensing element.

(a)

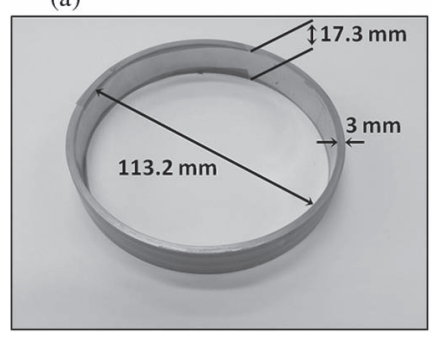

(b)

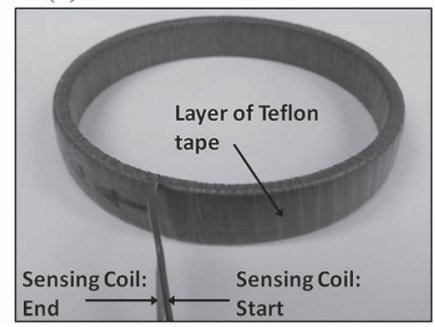

Fig. 3. Cryogenic permalloy core of optimized dimensions (a) and final preparation with sensing coil and Teflon insulation tape (b).

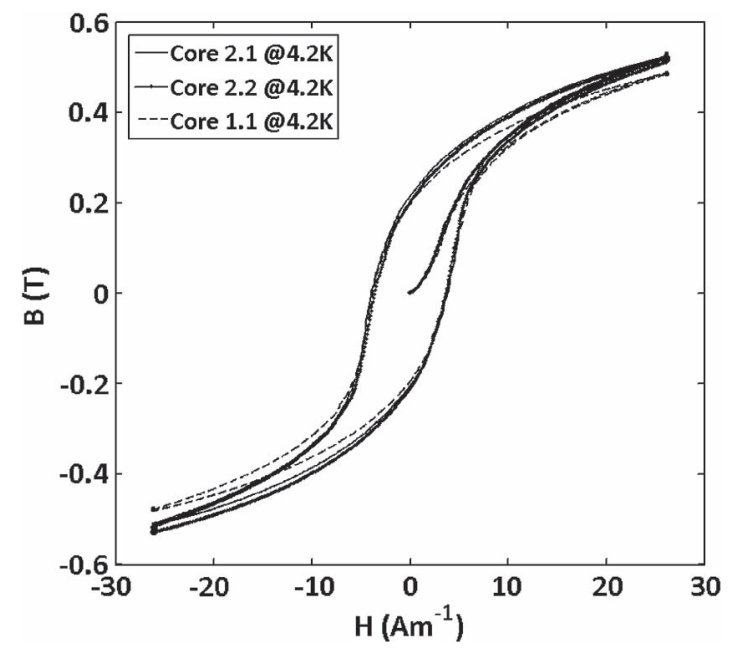

Fig. 4. Measured hysteresis loop for the cores 2.1, 2.2, and 1.1 at 4.2 K.

The uniformity of the cryogenic permalloy magnetic characteristics was assessed through hysteresis loop measurements. In Fig. 4, the hysteresis loop measured at $4.2 \mathrm{~K}$, for a maximum excitation field of $27 \mathrm{Am}^{-1}$ (the measurement set-up is described in [15]), of the three CryoDCCT's cores is shown (out of a batch of six cores): Differences are within $8 \%$. The only remarkable difference of these results, compared to the $\mu$-metal characteristics at room temperature, is a smaller residual field of $30 \%$.

The off-centering issue was addressed by implementing a $2 \mathrm{~mm}$ thick cylindrical pure iron shell at the location where the three cores are housed (Fig. 5(a)) and enclosed (Fig. 5(b)). (a)

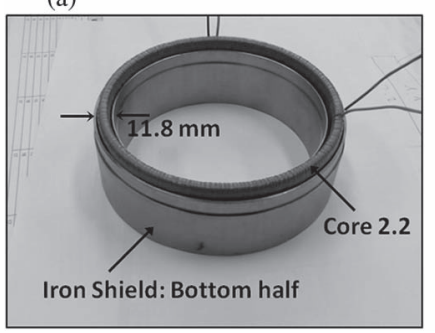

(b)

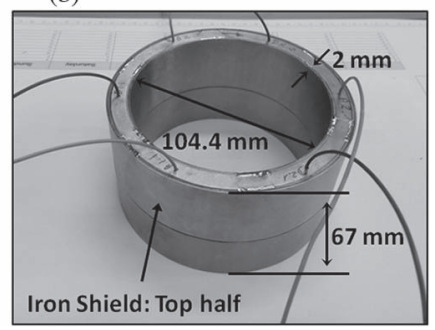

Fig. 5. Housing (a) and enclosing (b) of the cores into the iron shield: geometrical dimensions are also reported. (a)

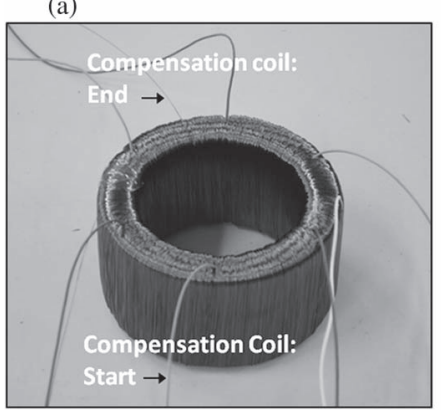

(b)

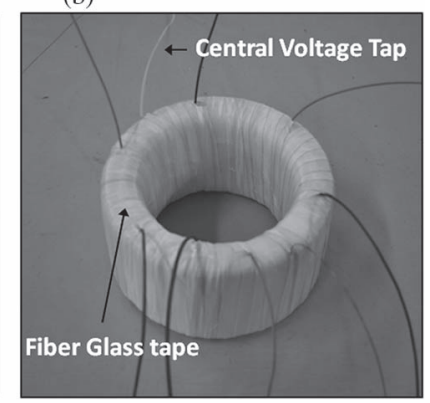

Fig. 6. Final CryoDCCT sensing element assembly: Superconducting compensation coil (a) with fiberglass tape (b); the wire from the central voltage tap is highlighted too.

Gauges of epoxyglass ( $1 \mathrm{~mm}$ thick) were used to center the cores into the cylinder.

The iron shield works up to an external magnetic field of $0.3 \mathrm{~T}$ and the expulsion of the external field is extended up to $1 \mathrm{~T}$ through a cylindrical superconducting shield made of an $\mathrm{MgB}_{2}$ bulk superconducting material. The design of the superconducting shield is described in [16] and the final object is being produced [24].

The need of an 8000 turns superconducting compensation coil arose from the requirements of limiting the unavoidable loss of bandwidth due to the increased secondary inductance and of reducing the cryogenic load. A copper wire would turn into excessive power dissipation, about $1 \mathrm{~W} / \mathrm{kA}$. Therefore, a $\mathrm{Nb}$-Ti superconducting wire capable of carrying $76 \mathrm{~A}$ at $4 \mathrm{~T}$ was chosen (referred to as type 1 LHC corrector strand, [25]). Probability of quench occurrence is minimized because the maximum expected working field is below 1 T. In Fig. 6(a), the final sensing element is shown. A voltage tap at the centre of the compensation coil was introduced for quench protection of the device (see Section III). A layer of fibreglass adhesive tape is used to minimize movements of the superconducting compensation coil, see Fig. 6(b).

\section{EXPERIMENTAL SETUP FOR DEVICE CHARACTERIZATION}

The achievement of a high accuracy CryoDCCT depends also on the preparatory work for the final assembly of the sensing element. In particular, before operation of the transducer, cores have to be fully demagnetized. Non-uniform residual magnetization can result into a high loss of accuracy and it may affect the stability of the device in the worst case. 


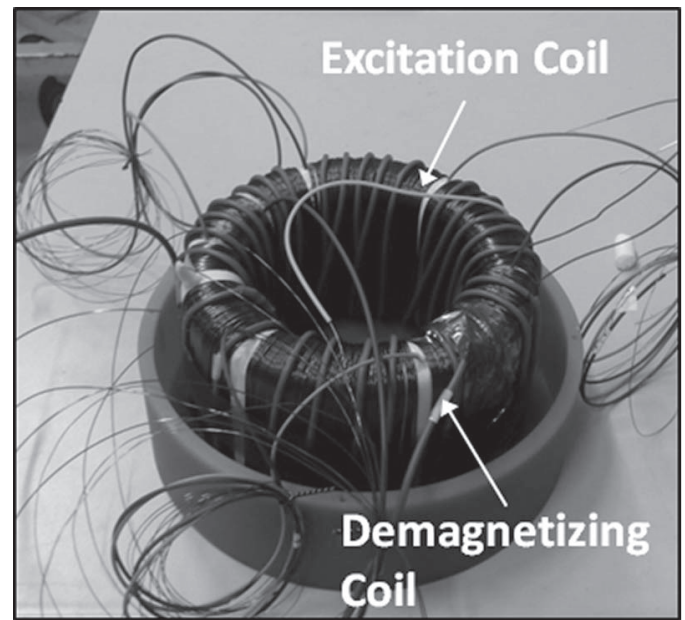

Fig. 7. CryoDCCT assembly for characterization measurements.

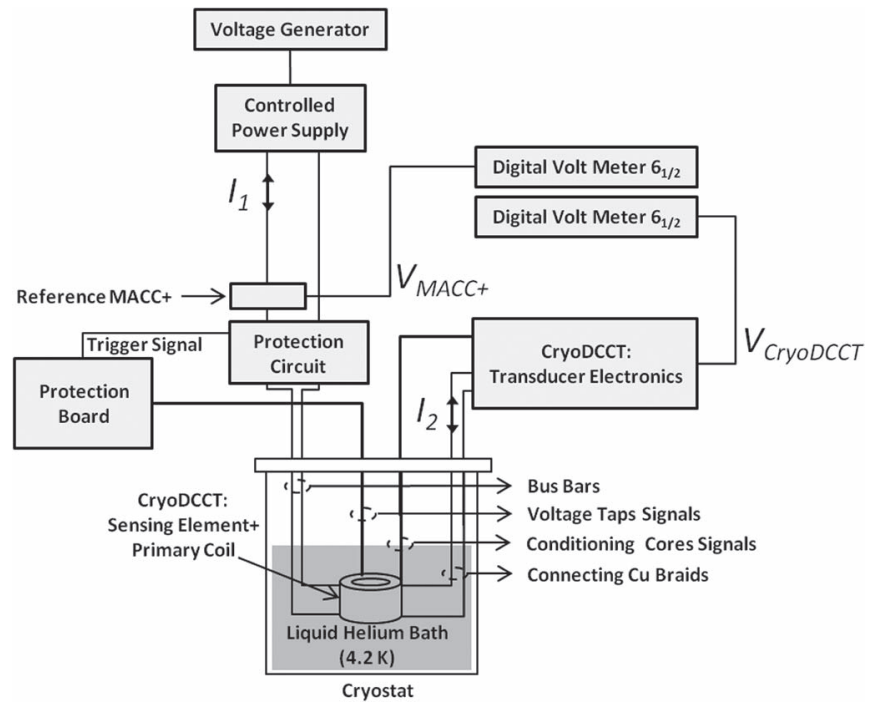

Fig. 8. Experimental setup for the CryoDCCT characterization.

To address this potential issue it is of foremost importance to wind an additional coil on the sensing element for demagnetization purposes.

For the characterization measurements, a 1000 turns excitation coil (cross section of $0.5 \mathrm{~mm}^{2}$ ) was wound on the top of the sensing element to achieve an equivalent primary current $\left(I_{1}\right)$ of $80 \mathrm{kA}$ for $80 \mathrm{~A}$ supplied. In other words, this coil is equivalent to a bus bar carrying a current up to $80 \mathrm{kA}$. Fig. 7 shows the sensing element with the excitation coil. Moreover, an additional 27 turns demagnetizing coil is depicted (insulated $\mathrm{Cu}$ wire with cross section of $1 \mathrm{~mm}^{2}$ ). The number of turns was chosen as a compromise between the minimum field available for demagnetization and the need of being able to overcome the maximum field generated by the continuity tests (maximum current used of $1 \mathrm{~mA}$ ).

In Fig. 8, the experimental setup for the characterization of the CryoDCCT final prototype is shown. The voltage Controlled Power Supply is (i) a high-accuracy \pm 40 A (from A\&D Products AG) device or (ii) a $\pm 125 \mathrm{~A}$ (from LakeShore, Mod. 622) power supply (control input $100 \mathrm{AV}^{-1}$ ). Both devices were used for the different tests that were carried out. The Voltage
Generator is a $\pm 10 \mathrm{~V}$ analogue output (16 bit- resolution) of a multipurpose NI board (NI PXI 6281). The reference DCCT is a MACC + [21]: Output $\pm 10 \mathrm{~V}$ for a primary of $\pm 120 \mathrm{~A}$, namely, $12 \mathrm{kAV}^{-1}$ considering the 1000 turns excitation coil. The value of $I_{1}$ is retrieved via the output voltage $\mathrm{V}_{\mathrm{MACC}+}\left(I_{1}\right)$ and the reading is carried out by means of the $6_{1 / 2}$-digits multimeter KEITHLEY 2000 (Digital Voltmeter).

The sensing element is placed in a cryogenic insert housed in a cryostat. The top plate of the cryostat provides the connection of the cables from/to the sensing element, the CryoDCCT transducer electronics, the bus bars for the excitation coil, and the $\mathrm{Cu}$ braids for the compensation coils. The voltage $\mathrm{V}_{\mathrm{CryoDCCT}}\left(I_{2}\right)$ is the output of the instrumentation amplifier: with the ideal gain of 16 , the voltage is proportional to $I_{2}$ through the equation

$$
\mathrm{V}_{\text {CryoDCCT }}\left(I_{2}\right)=G R_{\text {burden }} I_{2}
$$

that is, $\pm 8 \mathrm{~V}$ for a primary current of $\pm 80 \mathrm{kA}\left(10 \mathrm{kAV}^{-1}\right)$.

The reading of this voltage is carried out by means of a multimeter KEITHLEY 2000. The set-up includes the protection against quench of the superconducting compensation coil. A protection board, implementing a differential inductive voltage subtraction detection scheme developed at CERN, is used. When the difference of the voltage drop between the two halves of the compensation coil stays above $100 \mathrm{mV}$ for $10 \mathrm{~ms}$, the protection circuit is triggered by means of a $15 \mathrm{~V}$ signal. This notification allows a power switch to open the current path on the two bus bar branches, discharging the primary current (a $12 \mathrm{~V}$ bi-directional transient suppressor diode is used for overvoltage protection). Electrical connection can be established back via a manual reset. Direct cutting of the CryoDCCT current was not considered to avoid current unbalances during discharge that can bring cores in deep saturation. Resistance build-up in the superconducting wire is not of concern, as long as the collector-emitter voltage drop of a power amplifier's output transistor is higher than the specific collector-emitter saturation voltage.

\section{Test Campaign Results}

The aim of the characterization test campaign was twofold: a) the steady state characteristic of the CryoDCCT was assessed through the difference between the device reading and the values from the reference DCCT at specific current plateaus; b) current ramp-up measurements were carried out to identify the rated current of the new device.

In Table I the results of the static characterization, using the \pm 40 A primary power supply, up to a current of $20 \mathrm{kA}$ in the secondary are reported. The maximum testing current was limited by the heating up of the excitation coil (wound with copper wire). In other words, leaving a current plateau higher than $20 \mathrm{kA}$ for several seconds induced a quench in the superconducting compensation coil. The current in the excitation coil $I_{1}$ was ramped up from $1 \mathrm{kA}$ to $20 \mathrm{kA}$, with intermediate plateaus of $3 \mathrm{kA}, 5 \mathrm{kA}$, and $10 \mathrm{kA}$, and back to $1 \mathrm{kA}$ five times. On each current plateau both the reference $I_{1}$ and the secondary current $I_{2}$ were recorded, setting the sample frequency of the multimeter at the slowest rate (one reading per second) to increase the rejection to noise. The data were corrected from the 
TABLE I

Measured Reference Primary CurRent $I_{1}$ And Secondary CURRENT $I_{2}$ ALONG With THE RElative UnCERTAINTIES $\left(\mathrm{u}\left(I_{i}\right) / I_{i}\right)$ AND ERROR $\left(\left(I_{1}-I_{2}\right) / I_{1}\right)$

\begin{tabular}{rcrcc}
\hline \hline \multicolumn{1}{c}{$I_{I}(\mathrm{~A})$} & $\mathrm{u}\left(I_{I}\right) / I_{I} \mathrm{ppm}$ & \multicolumn{1}{c}{$I_{2}(\mathrm{~A})$} & $\mathrm{u}\left(I_{2}\right) / I_{2} \mathrm{ppm}$ & $\left(I_{I}-I_{2}\right) / I_{I} \%$ \\
\hline 998.4744 & 36 & 996.3080 & 44 & 0.22 \\
$2,997.5520$ & 22 & $2,991.0200$ & 28 & 0.22 \\
$4,996.6560$ & 11 & $4,985.6200$ & 17 & 0.22 \\
$9,995.9520$ & 14 & $9,973.7600$ & 11 & 0.22 \\
$19,992.9600$ & 3 & $19,948.9000$ & 22 & 0.22 \\
$9,996.1440$ & 10 & $9,973.9400$ & 11 & 0.22 \\
$4,996.7280$ & 13 & $4,985.7200$ & 26 & 0.22 \\
$2,996.7408$ & 641 & $2,990.9400$ & 30 & 0.19 \\
998.4336 & 20 & 996.3240 & 120 & 0.21 \\
\hline
\end{tabular}

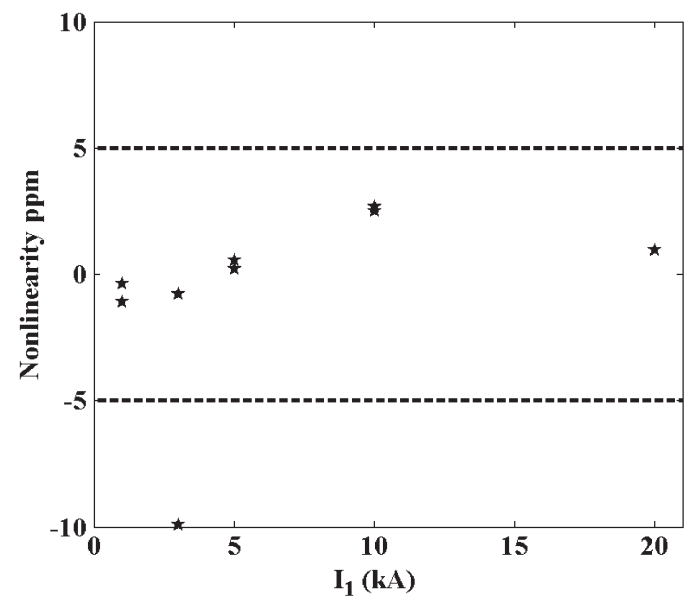

Fig. 9. CryoDCCT nonlinearity in ppm $\left(10^{-6}\right)$ of the measurement range (80 kA).

offset of the two instruments, $-2.16 \pm 0.12$ A for the reference DCCT and $+1.9 \pm 0.2$ A for the CryoDCCT, respectively. The experimental relative uncertainty, $\mathrm{u}\left(I_{i}\right) / I_{i}$, of the measured $I_{1}$ and $I_{2}$ are reported in ppm $\left(10^{-6}\right)$. The uncertainties from the reference DCCT and the CryoDCCT are of the same order of magnitude, i.e. less than $50 \mathrm{ppm}$ (neglecting two values out of bounds). In the last column of Table I, the error, which is the difference between $I_{1}$ and $I_{2}$, relative to reference $I_{1}$ is reported. It is worth to highlight that this error is almost constant and it can be assumed to be $0.22 \%$. This means the CryoDCCT shows a gain error with respect to the reference DCCT. However, the error is systematic and therefore it can be corrected. In Fig. 9, the nonlinearity of the CryoDCCT is shown. In particular, the data are expressed in ppm $\left(10^{-6}\right)$ of the measurement range (80 kA). This highlights the good performance of the CryoDCCT, namely, nonlinearity of better than $5 \mathrm{ppm}$.

Finally, in Fig. 10 the result of a ramp-up current measurement is shown. The primary (dashed) and secondary (solid) current curves are acquired through two analogue inputs, $\pm 10 \mathrm{~V}$ with 16-bit resolution, of a multipurpose NI board (NI USB-6363) at a sample frequency of $1 \mathrm{kS} / \mathrm{s}$. The current on the primary was ramped up, using the \pm 125 A power supply, with a effective ramp rate of $26 \mathrm{kAs}^{-1}$. This was the maximum
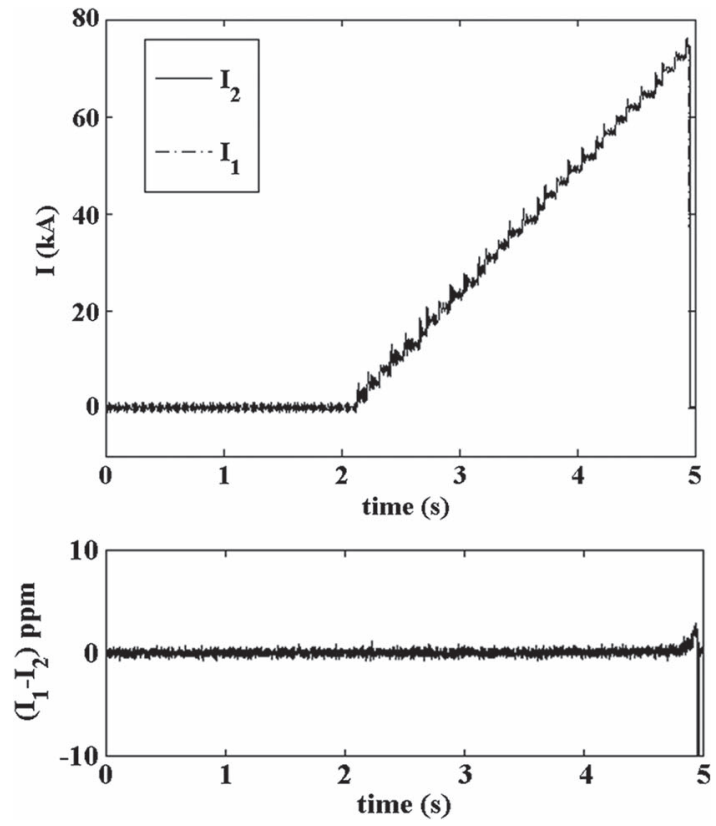

Fig. 10. Measured current (top) by means of the reference MACC+ (dashed) and cryogenic DCCT prototype (solid) during a current ramp-up cycle and relative difference (bottom) between the curves in ppm $\left(10^{-6}\right)$ of the measurement range $(80 \mathrm{kA})$.

ramp rate that allowed to avoid a quench of the compensation coil and to achieve almost the target of $80 \mathrm{kA}$. Indeed, a current of $76 \mathrm{kA}$ is reached before the compensation coil quenches (in Fig. 10 (top) the sudden drop to $0 \mathrm{~A}$ of the current due to the protection). Fig. 10 (bottom) shows the relative difference between the two curves referred to the range of $80 \mathrm{kA}$ : no appreciable differences between the reference DCCT and CryoDCCT are recognizable. The quench starts to develop where the difference between the curves deviates by about $1 \mathrm{ppm}$ (at the end of the ramp-up).

\section{COnClusion}

In this paper the design, assembly, and commissioning of a new cryogenic DC current transformer, capable of measuring currents of up to $80 \mathrm{kA}$ at $4.2 \mathrm{~K}$, is described. In particular, the design proposed in [15] is recalled, and assembly and commissioning of the new current transducer are described.

An experimental setup was conceived for the commissioning of the CryoDCCT. The primary of the CryoDCCT sensing element is wound with 1000 turns coil to reach $80 \mathrm{kA}$ for an excitation of $80 \mathrm{~A}$. The primary current reference is retrieved using a reference DC current transformer at room temperature.

Static metrological characterization up to $20 \mathrm{kA}$ highlighted outstanding performance of the proposed device, that is, measurement precision better than $50 \mathrm{ppm}$ and nonlinearity better than $5 \mathrm{ppm}$. Moreover, tests to inspect the device rated current were carried out and a current of $76 \mathrm{kA}$ was measured. The design target of $80 \mathrm{kA}$ was not reached due to limitations of the experimental setup, namely, overheating of the 1000 turns excitation coil. However, the effectiveness of the new CryoDCCT was completely proven.

The proposed transducer is going to be installed in the new insert at the FRESCA test station for the characterization of superconducting cables up to $80 \mathrm{kA}$. 


\section{ACKNOWLEDGMENT}

The authors thank C. Berriaud at CEA Saclay for fully supporting this development by transmitting the experience from his earlier work. The authors also thank M. Cerqueira Bastos, Greg Hudson, and M. Martino for their useful suggestions, availability, and cooperation, and Hitec for allowing intellectual property material to be used.

\section{REFERENCES}

[1] W. Buckel, CAS-CERN Accelerator School: 1st Superconductivity in Particle Accelerators Course. Geneva, Switzerland: CERN Publishing, 1989.

[2] A. P. Verweij et al., "1.9 K test facility for the reception of the superconducting cables for the LHC," IEEE Trans. Appl. Supercond., vol. 9, no. 2, pp. 153-156, Jun. 1999.

[3] A. G. Prodell and A. Am, "A Facility for evaluating superconductors above atmospheric pressure at 1.8K," Adv. Cryogenic Eng., vol. 43(A), pp. 443-450, 1998.

[4] P. Bruzzone et al., "Status report of the SULTAN test facility," IEEE Trans. Appl. Supercond., vol. 20, no. 3, pp. 455-457, Jun. 2010.

[5] B. A. Smith et al., "PTF, a new facility for pulse field testing of large scale superconducting cables and joints," IEEE Trans. Appl. Supercond., vol. 7, no. 2, pp. 1049-1052, Jun. 1997.

[6] A. P. Verweij, C-H. Denarie, S. Geminian, and O. Vincent-Viry, "Superconducting transformer and regulation circuit for the CERN cable test facility," J. Phys. Conf. Ser., vol. 43, no. 1, pp. 833-836, 2006.

[7] A. Godeke et al., "A superconducting transformer system for high current cable testing," Rev. Sci. Instrum., vol. 81, no. 3, Mar. 2010, Art. ID. 035107.

[8] J. Liu, "Manufacturing of $50 \mathrm{kA}$ superconducting transformer for ITER correction coil conductor test," Rev. Sci. Instrum., vol. 81, no. 4, Apr. 2010, Art. ID. 044701.

[9] C. Berriaud, S. Regnaud, and L. Vieillard, "High current test facility for superconductors at Saclay," IEEE Trans. Appl. Supercond., vol. 11, no. 1, pp. 3190-3193, Mar. 2001.

[10] M. Calvi et al., "Preparatory work to host the EDIPO test facility at CRPP," IEEE Trans. Appl. Supercond., vol. 18, no. 2, pp. 204-207, Jun. 2008.
[11] P. Arpaia, L. Bottura, G. Montenero, and S. La Naour, "Performance improvement of a measurement station for superconducting cable test," Rev. Sci. Instrum., vol. 83, no. 9, Sep. 2012, Art. ID. 095111.

[12] A. Ballarino, G. Montenero, and P. Arpaia, "Transformer-based measurement of critical currents in superconducting cables: Tutorial 51," IEEE Instrum. Meas. Mag., vol. 17, no. 1, pp. 49-55, Feb. 2014.

[13] C. Berriaud et al., "Test up to $80 \mathrm{kA}$ of an Al-stabilized NbTi cable with the upgraded Saclay superconducting transformer," IEEE Trans. Appl. Supercond., vol. 24, no. 3, Jun. 2014, Art. ID. 9500705.

[14] C. Berriaud and A. Donati, "A device for measuring high current at cryogenic temperatures," IEEE Trans. Appl. Supercond., vol. 12, no. 1, pp. 1264-1268, Mar. 2002.

[15] P. Arpaia, A. Ballarino, L. Bottura, and G. Montenero, "A cryogenic sensing element for measurement current transformers," J. Instrum., vol. 9, no. 3, Mar. 2014, Art. ID. P03011.

[16] P. Arpaia, A. Ballarino, G. Giunchi, and G. Montenero, " $\mathrm{MgB}_{2}$ cylindrical superconducting shielding for cryogenic measurement applications: A case study on DC current transformers," J. Instrum., vol. 9, no. 4, Apr. 2014, Art. ID. P04020.

[17] A. Hobson, "The zero-flux current transformer," Power App. Syst. III, Trans. Amer. Inst. Elect. Eng., vol. 72, no. 2, pp. 608-613, Jan. 1953.

[18] P. Daponte, "Electronically compensated current transformer modelling," Measurement, vol. 15, no. 4, pp. 213-222, Jul. 1995

[19] F. C. Williams and S. W. Noble, "The fundamental limitation of secondharmonic type of magnetic modulator as applied to the amplification of small DC signals," Proc. Inst. Elect. Eng._II, Power Eng., vol. 97, no. 58, pp. 445-459, Aug. 1950.

[20] M. Cerqueira Bastos et al., "High accuracy current masurements in the main power COnverters of the large handron collider: Tutorial 53," IEEE Instrum. Meas. Mag., vol. 17, no. 1, pp. 66-73, Feb. 2014

[21] MACC-PLUS, overview available since 13/02/2013. [Online]. Available: http://www.hitecups.com/assets/SMS/3_Products/Manuals/ Manual\%20MACC\%20plus.pdf

[22] K. Unser, "Beam current transformer with D.C. to $200 \mathrm{MHz}$ range," IEEE Trans. Nucl. Sci., vol. NS-16, no. 3, pp. 934-938, Jun. 1969.

[23] Nickel Iron and Cobalt Iron Cold Rolled Strips, overview available since 13/02/2013. [Online]. Available: http://www.aperam.com/ alloysandspecialities/fileadmin/pdf/Aperam/Brochure/CRYOPHY_R_.pdf

[24] G. Giunchi, G. Montenero, A. Figini Albisetti, and A. Ballarino, "Magnetic shielding and field trapping of a superconducting $\mathrm{MgB} 2$ cylinder in a transversal field," in Proc. Appl. Supercond. Conf., Charlotte, NC, USA, 2014, pp. 1-7.

[25] C. H. Denarie, A. Hilaire, and R. Wolf, "Critical current measurements of LHC superconducting corrector magnet strands," CERN, Geneva, Switzerland, AT-MEL Technical Note EDMS: 564604, Jan. 31, 2005. 